\title{
EVALUASI STANDAR JALUR EVAKUASI KEBAKARAN PADA BANGUNAN GEDUNG BERTINGKAT (Studi Kasus Gedung BAPPEDA Kabupaten Nagan Raya)
}

\author{
Zakia $^{1)}$, Rahmat Djamaluddin ${ }^{2)}$, Firzan $^{3)}$, Aulil Fajri ${ }^{4)}$ \\ 1, 2, 3,4) Program Studi Teknik Sipil Universitas Teuku Umar \\ Jalan Alue Peunyareng Desa Ujong Tanoh Darat, Meulaboh 23615

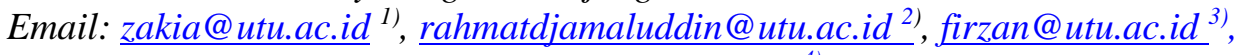 \\ aulilfajri40@gmail.com $^{4)}$
}

DOI: http://dx.doi.org/10.29103/tj.v11i2.551

(Received: June 2021 / Revised: August 2021 / Accepted: September 2021)

\begin{abstract}
Abstrak
Dampak negatif yang ditimbulkan dari bencana dapat berupa kerugian materiil maupun jiwa. Bencana tersebut dapat dicontohkan seperti banjir, gempa bumi ada pula bencana non alam seperti kebakaran. Penelitian ini bertujuan untuk mengetahui bagaimana kondisi standar jalur evakuasi kebakaran pada kantor BAPPEDA Kabupaten Nagan Raya, mengetahui apakah jalur evakuasi kebakaran pada kantor BAPPEDA Kabupaten Nagan Raya telah memenuhi standar. Data yang digunakan berupa data primer dan sekunder, yang diambil dengan cara penyebaran kuisioner, observasi dan pengamatan secara langsung. Pertanyaan melalui kuisioner diolah menggunakan software SPSS-23, sedangkan data hasil observasi dan pengamatan secara langsung, diolah melalui analisa deskripsi sesuai hasil lapangan. Hasil analisa menunjukkan bahwa semua pertanyaan valid memiliki nilai korelasi lebih besar dari nilai product moment/r tabel 0,632. Sedangkan metode penelitian yang digunakan adalah metode kuantitatif. Hasil evaluasi standar jalur evakuasi kebakaran pada Bangunan Gedung BAPPEDA Kabupaten Nagan Raya, belum sesuai standar Peraturan Menteri Pekerjaan Umum No.26/PRT/M/2008 tentang Persyaratan Teknis Sistem Proteksi Kebakaran Pada Bangunan Gedung dan Lingkungan bahwasanya penerapan peraturan sistem jalur evakuasi kebakaran masih pasif pada gedung BAPPEDA Kabupaten Nagan Raya untuk fungsi bangunan publik serta Kesesuaian fasilitas jalur evakuasi kebakaran yang tersedia pada bangunan gedung BAPPEDA Kabupaten Nagan Raya sangat sulit dilakukan evakuasi jika sewaktu waktuwaktu terjadi kebakaran
\end{abstract}

Kata Kunci: Jalur evakuasi, bangunan gedung, metode kuantitatif, kuisioner

\begin{abstract}
The negative impact can be in the form of material and life losses. The disaster can be exemplified as floods, earthquakes there are also non-natural disasters such as fire. Disaster is a phenomenon of human life that cannot be known exactly when it happened. This study aims to determine how the standard conditions of fire evacuation routes at the Nagan Raya Regency Bappeda office, find out whether the fire evacuation routes at the Nagan Raya Regency Bappeda office meet the standards. The data used in this study are primary and secondary data, data collection is done by observation and direct observation. While the research method used is a quantitative method. Results of the Standard Identification of Fire Evacuation Paths in Nagan Raya Regency Bappeda Building, according to Minister of Public Works Regulation No.26 / PRT / M / 2008 concerning Rescue Lines that the application of fire evacuation system regulations is
\end{abstract}

Evaluasi Standar Jalur Evakuasi Kebakaran Pada Bangunan Gedung Bertingkat (Studi Kasus Gedung BAPPEDA Kabupaten Nagan Raya) - Zakia, Rahmat Djamaluddin, Firzan, Aulil Fajri 
still passive in Bappeda Building Nagan Raya Regency for public building functions as well as the suitability of fire evacuation route facilities available in the building of Bappeda Nagan Raya Regency, it is very difficult to evacuate if at any time there is a fire

Keywords: Evacuation route, building, quantitative method, questionnaire

\section{Latar Belakang}

Kebakaran merupakan salah satu peristiwa yang tidak diinginkan dan terkadang tidak terkendali oleh karena sifatnya yang membahayakan dan menganggu kehidupan dan penghidupan masyarakat, maka kebakaran di kategorikan sebagai salah satu bentuk bencana, menurut Badan Nasional Penaggulangan Bencana (BNPB) adalah peristiwa yang mengancam dan menganggu kehidupan dan penghidupan masyarakat yang disebabkan oleh faktor alam, faktor non alam ataupun faktor kemanusiaan sehingga mengakibatkan timbulnya korban jiwa, kerusakan lingkungan dan kerugian harta benda.

Badan Perencanaan Pembangunan Daerah (BAPPEDA) Nagan Raya merupakan salah satu kantor pemerintahan yang bertugas merencanakan pembangunan daerah sehingga sasaran yang diinginkan dapat tercapai dengan baik. Kantor BAPPEDA Kabupaten Nagan Raya terletak di jalan poros utama suka makmue, yang terdiri dari 2 (dua) lantai dengan jumlah karyawan sebanyak 80 orang (Bappeda Nagan Raya, 2020). Berdasarkan Peraturan Pemerintah No. 36 Tahun 2005 tentang Peraturan Pelaksanaan Undang Undang No. 28 Tahun 2002 serta Qanun No. 10 Tahun 2011 tentang Bangunan Gedung mengatakan bahwa setiap bangunan gedung, kecuali rumah tinggal tunggal dan rumah deret sederhana, harus menyediakan sarana evakuasi yang meliputi sistem peringatan bahaya bagi pengguna, pintu keluar darurat dan jalur evakuasi yang dapat menjamin kemudahan pengguna bangunan gedung untuk melakukan evakuasi dari dalam bangunan gedung secara aman apabila terjadi bencana atau keadaan darurat. Kebakaran yang sering terjadi pada Gedung Pemerintahan membuat kita harus selalu waspada dan juga merugikan dari segi anggaran di mana pemerintah akan mengalokasikan dana lagi agar bangunan yang telah terbakar dapat difungsikan kembali, oleh karena itu perlu dilakukan evaluasi terhadap bangunan gedung BAPPEDA Kabupaten Nagan Raya terhadap standar jalur evakuasi kebakaran sesuai dengan Peraturan Pemerintah No. 36 Tahun 2005 tentang Peraturan Pelaksanaan Undang Undang No. 28 Tahun 2002 agar dapat meminimalisir tingkat kerugian yang terjadi baik dari segi materiil maupun non materiil.

\section{Metode Penelitian}

Tahapan penelitian yang dilakukan pada evaluasi ini dimulai dengan mengumpulkan data selanjutnya dilakukan persiapan untuk mendapatkan tahapan informasi dengan mengumpulkan data primer dan data sekunder. Setelah data terkumpul dilakukan pengolahan data dengan menggunakan metode Kuantitatif.

\subsection{Teknik Sampling}

Pengambilan sampel dalam penelitian ini menggunakan teknik pengambilan sampel probability sampling, yaitu teknik sampling yang memberikan peluang yang sama bagi setiap unsur (anggota) populasi untuk dipilih menjadi sampel,

Evaluasi Standar Jalur Evakuasi Kebakaran Pada Bangunan Gedung Bertingkat (Studi Kasus Gedung BAPPEDA Kabupaten Nagan Raya) - Zakia, Rahmat Djamaluddin, Firzan, Aulil Fajri 
dengan metode simple random sampling, teknik ini dikatakan sederhana (simple) karena cara pengambilan sampel dari semua anggota populasi dilakukan secara acak tanpa memperhatikan strata yang ada dalam populasi itu (Sekaran, 2007). Menurut Margono, (2004) teknik sampling adalah cara untuk menentukan sampel yang jumlahnya sesuai dengan ukuran sampel yang akan dijadikan sumber data sebenarnya, dengan memperhatikan sifat-sifat dan penyebaran populasi agar diperoleh sampel yang representatif.

\subsection{Skala Likert}

Skala Likert merupakan suatu skala psikometrik yang umumnya dilakukan dalam kuisioner, menerbitkan suatu laporan yang menjelaskan penggunaannya. Akdon dan Riduan, (2010) mengatakan Skala Likert digunakan untuk mengukur sikap, pendapat dan persepsi seseorang atau sekelompok orang terhadap variabel penelitian. Dengan Skala Likert maka variabel yang akan diukur dijabarkan menjadi indikator variabel. Jawaban setiap item instrumen mempunyai gradasi dari sangat positif sampai sangat negatif. Setiap jawaban dihubungkan dengan bentuk pernyataan atau dukungan sikap. Untuk keperluan analisis kuantitatif, maka jawaban dapat diberi skor seperti terlihat pada Tabel 1.

Tabel 1 Skala likert

\begin{tabular}{cc}
\hline Tingkat Kesetujuan & Poin \\
\hline Sangat Setuju & 1 \\
\hline Setuju & 2 \\
\hline Netral & 3 \\
\hline Tidak Setuju & 4 \\
\hline Sangat Tidak Setuju & 5 \\
\hline Sumber: Akdon dan Riduan, (2010)
\end{tabular}

\subsection{Pengumpulan data}

Tahapan pengumpulan data dimulai dengan proses survei lapangan dilakukan dengan meninjau langsung ke seluruh lokasi bangunan gedung BAPPEDA Kabupaten Nagan Raya untuk mencari informasi faktual secara mendetail pada jalur evakuasi serta parameter yang tersedia di gedung BAPPEDA Kabupaten Nagan Raya

Tahapan kedua adalah observasi atau pengamatan secara langsung. Pada tahap ini target pengamatan berupa Pengamatan/observasi secara langsung dilakukan untuk melihat kondisi kelengkapan parameter pada jalur evakuasi sehingga dapat dievaluasi kesesuaian kelengkapan parameter jalur evakuasi kebakaran yang ada pada bangunan gedung kemudian dianalisa kesesuaian berdasarkan standar PERMEN PUPR No. 26/PRT/M/2008 Tahun 2008 tentang Persyaratan Teknis Sistem Proteksi Kebakaran pada Bangunan Gedung dan Lingkungan,

\subsubsection{Data primer}

Kegiatan pengumpulan data primer dilakukan dengan cara observasi metode survei yang bertujuan untuk mengumpulkan data untuk memperoleh data yang secara langsung dari obyek lokasi penelitian ada dua tahap pengumpulan data primer.

Evaluasi Standar Jalur Evakuasi Kebakaran Pada Bangunan Gedung Bertingkat (Studi Kasus Gedung BAPPEDA Kabupaten Nagan Raya) - Zakia, Rahmat Djamaluddin, Firzan, Aulil Fajri 
Tahapan pengumpulan data dimulai dengan proses survei lapangan dilakukan dengan meninjau langsung ke seluruh lokasi bangunan gedung untuk mencari informasi faktual secara mendetail pada jalur evakuasi serta parameter yang tersedia di gedung untuk mendapatkan hasil apakah sesuai dengan peraturan yang berlaku atau belum sesuai. Tahapan kedua adalah observasi langsung dilakukan untuk melihat kondisi kelengkapan parameter pada jalur evakuasi kebakaran yang sudah tersedia kemudian dianalisa kesesuaian berdasarkan standar PERMEN PUPR No. 26/PRT/M/2008 Tahun 2008 tentang Persyaratan Teknis Sistem Proteksi Kebakaran pada Bangunan Gedung dan Lingkungan. Data primer sebagai parameter berupa Spingkler otomatik; Pompa pemadam kebakaran; Penyediaan air; Alat Pemadam Api Ringan (APAR); Sistem deteksi dan alarm kebakaran dan sistem komunikasi; Pasangan konstruksi tahan api; Tangga; Pintu, bahan berlapis interiol; Penghalang api; Atrium dan Tanda petunjuk arah koridor serta Hidran

\subsubsection{Data sekunder}

Data sekunder adalah data penunjang yang dikumpulkan melalui studi kepustakaan, hasil penelitian terdahulu data dan lain sebagainya. Tujuan dari pengumpulan data sekunder ini adalah untuk mendapatkan data insatansional yang selanjutnya akan diolah dan dianalisa. Pada penelitian ini yang merupakan data sekunder adalah denah, foto dokumentasi, jumlah staf penghuni. Data sekunder yang diperoleh terdiri dari data-data pelengkap berupa Denah bangunan gedung; Peta lokasi penelitian; Foto dokumentasi

\subsection{Metode Analisis Data}

Metode analisis data pada penelitian ini dilakukan dengan cara sebagai berikut:

1. Analisis dari kondisi jalur evakuasi merupakan analisis yang bersifat kuantitatif, karena parameter-parameter yang berpengaruh dalam studi ini adalah parameter kuantitatif. Adapun cara peneliti untuk dapat meperoleh data hingga kemudian menganalisisnya adalah sebagai berikut :

a. Melakukan observasi langsung kepada objek penelitian untuk melihat jalur evakuasi.

b. Mendokumentasikan secara langsung hal-hal terkait dengan objek yang diteliti, yaitu mengenai kondisi jalur evakuasi.

c. Mencatat hal-hal penting terkait dengan kondisi jalur evakuasi.

2. Analisis sampling pada penelitian ini yaitu dengan menetapkan sampel berdasarkan pertimbangan atau kriteria-kriteia tertentu, yaitu sebagai berikut:

a. Sampel merupakan staf karyawan stockholder Gedung BAPPEDA Kabupaten Nagan Raya, berjumlah 10 (sepuluh) orang.

b. Sampel terdiri dari laki-laki dan perempuan yang bekerja sebagai staf karyawan pada Bangunan Gedung BAPPEDA Kabupaten Nagan Raya.

3. Skala pengukuran (Skala likert). Analisis ini merupakan metode analisis yang bersifat kuantitatif, sehingga data yang digunakan harus bersifat kuantitatif sedangkan pengolahan dan hasil yang didapat dari survey primer berupa data kualitatif, maka parameter tersebut harus dikonversikan ke dalam bentuk data kuantitatif. Berdasarkan penjelasan tersebut, maka digunakan analisis

Evaluasi Standar Jalur Evakuasi Kebakaran Pada Bangunan Gedung Bertingkat (Studi Kasus Gedung BAPPEDA Kabupaten Nagan Raya) - Zakia, Rahmat Djamaluddin, Firzan, Aulil Fajri 
pembobotan untuk mengkuantifikasi parameter kinerja, sehingga data tersebut dikatagorikan menjadi beberapa tingkatan dalam skala. Untuk memperoleh data hingga kemudian menginterpretasikannya adalah sebagai berikut :

a. Melakukan survei lokasi untuk mengamati secara langsung kondisi jalur evakuasi.

b. Merumusakan data populasi untuk penentuan jumlah sampel

c. Membuat pertanyaan kuisioner untuk disebarkan kepada responden.

d. Menyebarkan kuesioner kepada responden.

e. Mlakukan rekapitulasi jawaban kuesioner yang telah diisi oleh responden.

f. Melakukan perhitungan kuesioner dengan bantuan Microsoft Excel.

g. Melakukan pembahasan dan interpretasi data.

4. Pengolahan data hasil kuisioner dengan SPSS-23 yang mana langkah-langkah pengerjaan nya adalah sebagai berikut :

a. Langkah pertama adalah mengetahui terlebih dahulu skala apa yang digunakan pada kuisioner atau angket penelitian. Pada kasus ini angket atau kuisioner yang digunakan adalah skala likert sebagai berikut :

1) Sangat setuju (SS)

2) Setuju (S)

3) Netral (N)

4) Tidak setuju (TS)

5) Sangat tidak setuju (STS)

Ketentuan akan dirubah nilainya menjadi Sangat setuju (1) Setuju (2) Netral (3) Tidak setuju (4) Sangat tidak setuju (5) dengan catatan semua pernyataannya kalimat favorable.

b. Kuisioner yang telah diisi responden tersebut diinput langsung ke dalam spss.

c. Selanjutnya buka program spss

d. Klik menu "variabel view" pada spss

e. Isikan nama variabelnya begitu juga setiap itemnya

f. Selanjutnya klik menu " data view" pada SPSS

g. Langkah selanjutnya masukkan data hasil pembagian kuisioner yang telah diolah dengan microsoft excel.

\subsection{Pengolahan Data}

Tahapan pengolahan data dalam penelitian ini adalah setelah mendapatkan hasil dari mengenalisa dan mengevaluasi standar jalur evakuasi kebakaran kemudian membandingkan data yang ada di lapangan dengan ketentuan yang terdapat dalam Permen PUPR No. 26/PRT/M/2008 Tahun 2008 tentang Persyaratan Teknis Sistem Proteksi Kebakaran pada Bangunan Gedung dan Lingkungan. Metode pengumpulan data berupa suatu pernyataan tentang sifat, keadaan, kegiatan tertentu dan sejenisnya. Pengumpulan data dilakukan untuk mendapatkan suatu informasi yang dibutuhkan dalam mencapai tujuan penelitian.

\subsection{Uji Validitas dan Reliabilitas}

\subsubsection{Uji validitas}

Uji ini dilakukan dengan cara membandingkan kriteria angka $r$ hitung dan $r$ tabel. Jika $r$ hitung lebih besar dari $r$ tabel maka item dikatakan valid dan sebaliknya jika $\mathrm{r}$ hitung lebih kecil dari $\mathrm{r}$ tabel maka item dikatakan tidak valid. $\mathrm{R}$ hitung dicari

Evaluasi Standar Jalur Evakuasi Kebakaran Pada Bangunan Gedung Bertingkat (Studi Kasus Gedung BAPPEDA Kabupaten Nagan Raya) - Zakia, Rahmat Djamaluddin, Firzan, Aulil Fajri 
dengan menggunakan program SPSS, sedangkan $r$ tabel dicari dengan cara melihat tabel $r$ dengan ketentuan $r$ minimal adalah 0,3 (Sugiyono, 2015).

Tabel 2 Kriteria tingkat reliabilitas

\begin{tabular}{cc}
\hline Nilai & Keterangan \\
\hline $\mathrm{r}_{11<0,20}$ & Sangat rendah \\
\hline $0,20 \leq \mathrm{r}_{11<0,40}$ & Rendah \\
\hline $0,40 \leq \mathrm{r}_{11<0,70}$ & Sedang \\
\hline $0,70 \leq \mathrm{r}_{11<0,90}$ & Tinggi \\
\hline $0,90 \leq \mathrm{r}_{11<1}$ & Sangat Tinggi \\
\hline
\end{tabular}

Sumber: (Sugiyono, 2015)

Langkah-langkah dalam melakukann pengujian validitas pada software SPSS adalah sebagai berikut:

1. Buat skor total masing-masing variabel (Tabel perhitungan skor)

2. Klik Analyze -> Correlate -> Bivariate (Gambar/Output SPSS)

3. Masukan seluruh item variabel $x$ ke Variabels

4. Cek list Pearson; Two Tailed; Flag

5. Klik Ok

\subsubsection{Uji reliabilitas}

Uji ini dilakukan dengan cara membandingkan angka cronbach alpha dengan ketentuan nilai cronbach alpha minimal 0,6. Artinya jika nilai cronbach alpha yang didapatkan dari hasil perhitungan SPSS lebih besar dari 0,6 maka disimpulkan kuisioner tersebut reliabel, sebaliknya jika cronbach alpha lebih kecil dari 0,6 maka disimpulkan tidak reliabel.

Langkah-langkah yang dilakukan dalam pengujian reliabilitas dengan SPSS-

23 sebagai berikut:

1. Klik Analyze -> Scale -> Reliability Analysis

2. Masukan seluruh item variabel X ke Items

3. Pastikan pada model terpilih Alpha

4. Klik Ok

\section{Hasil dan Pembahasan}

3.1 Hasil

Hasil pada penelitian ini adalah mengevaluasi standar jalur evakuasi kebakaran, jenis-jenis parameter apa saja yang tersedia yang sesuaian dengan peraturan menteri serta faktor pendukung dan kendala tentang keadaan jalur evakuasi kebakaran.

\subsubsection{Penilaian responden terhadap gedung}

Responden adalah stakeholder BAPPEDA Nagan Raya yang berjumlah 10 (sepuluh) orang, jalur evakuasi adalah jalur khusus yang menghubungkan semua area ke area yang aman (titik kumpul). Dalam sebuah bangunan, jalur evakuasi sangatlah penting untuk mengevakuasi para penghuni ketempat yang aman apabila di dalam sebuah bangunan terjadi hal-hal yang tidak di inginkan, seperti kebakaran, gempa dan lain sebagainya. Oleh sebab itu, rambu-rambu jalur evakuasi harus dipasang di semua area bangunan.

Evaluasi Standar Jalur Evakuasi Kebakaran Pada Bangunan Gedung Bertingkat (Studi Kasus Gedung BAPPEDA Kabupaten Nagan Raya) - Zakia, Rahmat Djamaluddin, Firzan, Aulil Fajri 
Tabel 3 Hasil penilaian persepsi responden stockholder terhadap fasilitas jalur evakuasi digedung Bappeda Kabupaten Nagan Raya.

\begin{tabular}{|c|c|c|c|c|c|c|}
\hline \multirow[b]{2}{*}{ Pertanyaan } & \multicolumn{5}{|c|}{ Frekuensi Jawaban } & \multirow[b]{2}{*}{ Total } \\
\hline & $\begin{array}{l}\text { Sangat } \\
\text { Setuju }\end{array}$ & Setuju & Netral & $\begin{array}{l}\text { Tidak } \\
\text { Setuju }\end{array}$ & $\begin{array}{l}\text { Sangat } \\
\text { Tidak } \\
\text { Setuju }\end{array}$ & \\
\hline \multirow{2}{*}{$\begin{array}{l}\text { Fasilitas yang ada digedung bappeda } \\
\text { kabupaten nagan raya sudah aman } \\
\text { terhadap kebakaran }\end{array}$} & 2 & 5 & 3 & 0 & 0 & 10 \\
\hline & $20 \%$ & $50 \%$ & $30 \%$ & - & - & $100 \%$ \\
\hline \multirow{2}{*}{$\begin{array}{l}\text { Gedung bappeda kabupaten nagan raya } \\
\text { sudah memenuhi standar evakuasi } \\
\text { kebakaran }\end{array}$} & 2 & 4 & 4 & 0 & 0 & 10 \\
\hline & $20 \%$ & $40 \%$ & $40 \%$ & - & - & $100 \%$ \\
\hline \multirow{2}{*}{$\begin{array}{l}\text { Pintu darurat pada gedung bappeda } \\
\text { kabupaten nagan raya dapat dibuka dari } \\
\text { arah mana saja }\end{array}$} & 1 & 9 & 0 & 0 & 0 & 10 \\
\hline & $10 \%$ & $90 \%$ & - & - & - & $100 \%$ \\
\hline \multirow{2}{*}{$\begin{array}{l}\text { Pintu darurat dilengkapi dengan penutup } \\
\text { pintu otomatis }\end{array}$} & 2 & 3 & 2 & 3 & 0 & 10 \\
\hline & $20 \%$ & $30 \%$ & $20 \%$ & $30 \%$ & - & $100 \%$ \\
\hline \multirow{2}{*}{$\begin{array}{l}\text { Setiap bangunan pemerintah/ bangunan } \\
\text { publik diharuskan untuk menyediakan } \\
\text { jalur evakuasi kebakaran. }\end{array}$} & 5 & 3 & 0 & 2 & 0 & 10 \\
\hline & $50 \%$ & $30 \%$ & - & $20 \%$ & - & $100 \%$ \\
\hline
\end{tabular}

Hasil data angket (kuisioner) menunjukan bahwa sebagian besar responden sangat setuju adanya program fasilitas jalur evakuasi di gedung BAPPEDA Kabupaten Nagan Raya, hal tersebut seperti diperlihatkan pada Gambar 1.

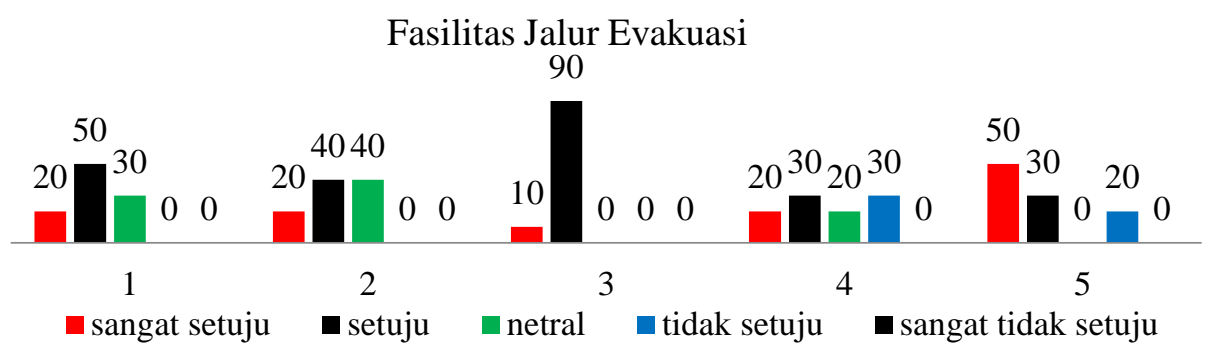

Gambar 1 Grafik persentase penilaian responden pada fasilitas jalur evakuasi

Data tentang variabel pernilaian terhadap program fasilitas jalur evakuasi oleh responden yang merupakan stakeholder dan ahli di BAPPEDA berjumlah 10 orang:

1) Fasilitas yang ada digedung bappeda kabupaten nagan raya sudah aman terhadap kebakaran, menurut penilaian responden menyatakan $20 \%$ sangat setuju, $50 \%$ setuju, dan $30 \%$ Netral.

2) Gedung bappeda kabupaten nagan raya sudah memenuhi standar evakuasi kebakaran, menurut penilaian responden menyatakan $20 \%$ sangat setuju, $40 \%$ setuju, dan $40 \%$ Netral.

3) Pintu darurat pada gedung bappeda kabupaten nagan raya dapat dibuka dari arah mana saja, menurut penilaian responden menyatakan $10 \%$ sangat setuju, dan $90 \%$ setuju.

4) Pintu darurat dilengkapi dengan penutup pintu otomatis, menurut penilaian responden menyatakan $20 \%$ sangat setuju, 30\% setuju, 20\% Netral, dan $30 \%$ Tidak Setuju.

5) Setiap bangunan pemerintah/bangunan publik diharuskan untuk menyediakan jalur evakuasi kebakaran, menurut penilaian responden menyatakan 50\% sangat setuju, 30\% setuju, dan $20 \%$ tidak setuju.

Evaluasi Standar Jalur Evakuasi Kebakaran Pada Bangunan Gedung Bertingkat (Studi Kasus Gedung BAPPEDA Kabupaten Nagan Raya) - Zakia, Rahmat Djamaluddin, Firzan, Aulil Fajri 
Dari lima aspek yang dinilai pada fasilitas jalur evakuasi, dapat dijabarkan secara global bahwa responden menyatakan $24 \%$ sangat setuju, $48 \%$ setuju, $18 \%$ Netral, dan $10 \%$ tidak setuju.

Tabel 4 Hasil penilaian persepsi responden stakeholder dan 10 ahli

\begin{tabular}{|c|c|c|c|c|c|c|}
\hline \multirow[b]{2}{*}{ Pertanyaan } & \multicolumn{5}{|c|}{ Frekuensi Jawaban } & \multirow[b]{2}{*}{ Total } \\
\hline & $\begin{array}{l}\text { Sangat } \\
\text { Setuju }\end{array}$ & Setuju & Netral & $\begin{array}{l}\text { Tidak } \\
\text { Setuju }\end{array}$ & $\begin{array}{c}\text { Sangat } \\
\text { Tidak } \\
\text { Setuju } \\
\end{array}$ & \\
\hline \multirow{2}{*}{$\begin{array}{l}\text { Kurangnya kepedulian terhadap } \\
\text { penerapan jalur evakuasi pada Gedung } \\
\text { bappeda kabupaten nagan raya. }\end{array}$} & 0 & 2 & 8 & 0 & 0 & 10 \\
\hline & - & $20 \%$ & $80 \%$ & - & - & $100 \%$ \\
\hline \multirow{2}{*}{$\begin{array}{l}\text { Dilakukan pelatihan tentang tata cara } \\
\text { penempatan simbol/ fasilitas jalur } \\
\text { evakuasi pada Gedung bappeda } \\
\text { kabupaten nagan raya sudah }\end{array}$} & 2 & 5 & 3 & 0 & 0 & 10 \\
\hline & $20 \%$ & $50 \%$ & $30 \%$ & - & - & $100 \%$ \\
\hline \multirow{2}{*}{$\begin{array}{l}\text { Kurang menyadari manfaat dari jalur } \\
\text { evakuasi. }\end{array}$} & 0 & 4 & 2 & 4 & 0 & 10 \\
\hline & - & $40 \%$ & $20 \%$ & $40 \%$ & - & $100 \%$ \\
\hline \multirow{2}{*}{$\begin{array}{l}\text { Kurangnya pengetahuan dan } \\
\text { pengalaman mengenai jalur evakuasi }\end{array}$} & 0 & 4 & 0 & 6 & 0 & 10 \\
\hline & - & $40 \%$ & - & $60 \%$ & - & $100 \%$ \\
\hline \multirow{2}{*}{$\begin{array}{l}\text { Semua penghuni paham mengenai } \\
\text { kegunaan simbol jalur evakuasi }\end{array}$} & 3 & 4 & 3 & 0 & 0 & 10 \\
\hline & $30 \%$ & $40 \%$ & $30 \%$ & - & - & $100 \%$ \\
\hline \multirow{2}{*}{$\begin{array}{l}\text { Semua mengerti menggunakan APAR } \\
\text { jika sewaktu-waktu terjadi kebakaran }\end{array}$} & 2 & 3 & 5 & 0 & 0 & 10 \\
\hline & $20 \%$ & $30 \%$ & $50 \%$ & - & - & $100 \%$ \\
\hline
\end{tabular}

Hasil data angket (kuisioner) menunjukan bahwa sebagian besar responden sangat setuju terhadap manfaat dari jalur evakuasi di gedung bappeda kabupaten nagan raya dapat dilihat pada Gambar 2.

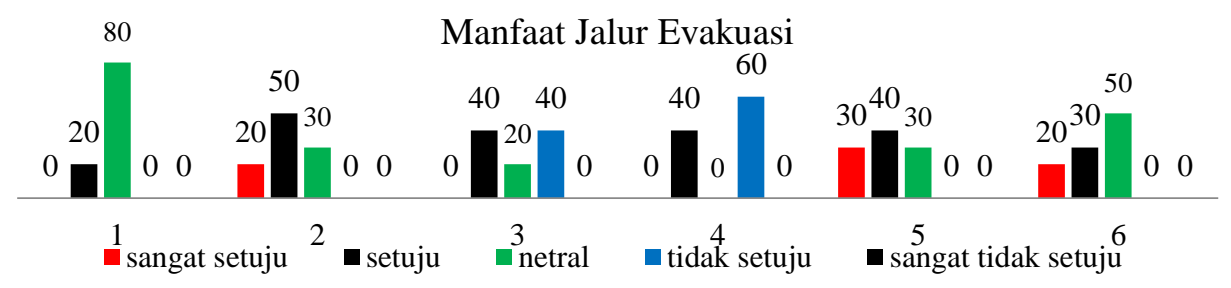

Gambar 2 Grafik persentase penilaian responden pada manfaat jalur evakuasi

Berikut data tentang variabel pernilaian terhadap manfaat jalur evakuasi sebagai berikut:

1) Kurangnya kepedulian terhadap penerapan jalur evakuasi pada Gedung Bappeda kabupaten Nagan Raya, menurut penilaian responden menyatakan $20 \%$ setuju dan $80 \%$ netral.

2) Dilakukan pelatihan tentang tata cara penempatan simbol/fasilitas jalur evakuasi pada Gedung Bappeda kabupaten Nagan Raya sudah, menurut penilaian responden menyatakan 20\% sangat setuju dan 50\% setuju dan $30 \%$ netral.

3) Kurang menyadari manfaat dari jalur evakuasi, menurut penilaian responden menyatakan $40 \%$ setuju, $20 \%$ netral, $40 \%$ tidak setuju.

4) Kurangnya pengetahuan dan pengalaman mengenai jalur evakuasi, menurut penilaian responden menyatakan $40 \%$ setuju, dan $60 \%$ Tidak Setuju.

Evaluasi Standar Jalur Evakuasi Kebakaran Pada Bangunan Gedung Bertingkat (Studi Kasus Gedung BAPPEDA Kabupaten Nagan Raya) - Zakia, Rahmat Djamaluddin, Firzan, Aulil Fajri 
5) Semua penghuni paham mengenai kegunaan simbol jalur evakuasi, menurut penilaian responden menyatakan $30 \%$ sangat setuju, $40 \%$ setuju, dan $30 \%$ netral.

6) Semua mengerti menggunakan APAR jika sewaktu-waktu terjadi kebakaran, menurut penilaian responden menyatakan $20 \%$ sangat setuju, $30 \%$ setuju, $50 \%$ netral.

Dari enam aspek yang dinilai pada manfaat jalur evakuasi, dapat dijabarkan secara global bahwa responden menyatakan $12 \%$ sangat setuju, 37\% setuju, 35\% netral dan $17 \%$ tidak setuju.

Tabel 5 Hasil penilaian persepsi responden

\begin{tabular}{|c|c|c|c|c|c|c|}
\hline \multirow[b]{2}{*}{ Pertanyaan } & \multicolumn{5}{|c|}{ Frekuensi Jawaban } & \multirow[b]{2}{*}{ Total } \\
\hline & $\begin{array}{l}\text { Sangat } \\
\text { Setuju }\end{array}$ & Setuju & Netral & $\begin{array}{l}\text { Tidak } \\
\text { Setuju }\end{array}$ & $\begin{array}{c}\text { Sangat Tidak } \\
\text { Setuju }\end{array}$ & \\
\hline \multirow{2}{*}{$\begin{array}{l}\text { Jalur evakuasi sangat penting } \\
\text { diterapkan pada bangunan } \\
\text { pemerintah/bangunan publik. }\end{array}$} & 5 & 5 & 0 & 0 & 0 & 10 \\
\hline & $50 \%$ & $50 \%$ & - & - & - & $100 \%$ \\
\hline \multirow{2}{*}{$\begin{array}{l}\text { Jalur evakuasi dilengkapi dengan } \\
\text { penanda yang jelas dan mudah terlihat }\end{array}$} & 5 & 3 & 2 & 0 & 0 & 10 \\
\hline & $50 \%$ & $30 \%$ & $20 \%$ & - & - & $100 \%$ \\
\hline \multirow{2}{*}{$\begin{array}{l}\text { Jalur evakuasi bebas dari benda yang } \\
\text { mudah terbakar atau benda yang dapat } \\
\text { membahayakan }\end{array}$} & 5 & 1 & 2 & 2 & 0 & 10 \\
\hline & $50 \%$ & $10 \%$ & $20 \%$ & $20 \%$ & - & $100 \%$ \\
\hline \multirow{2}{*}{$\begin{array}{l}\text { Jalur evakuasi tidak melewati ruang } \\
\text { yang dapat dikunci }\end{array}$} & 3 & 7 & 0 & 0 & 0 & 10 \\
\hline & $30 \%$ & $70 \%$ & - & - & - & $100 \%$ \\
\hline
\end{tabular}

Hasil data angket (kuisioner) menunjukan bahwa sebagian besar responden sangat setuju adanya standar jalur evakuasi di gedung Bappeda Kabupaten Nagan Raya dapat dilihat pada Gambar 3.

Standar Jalur Evakuasi

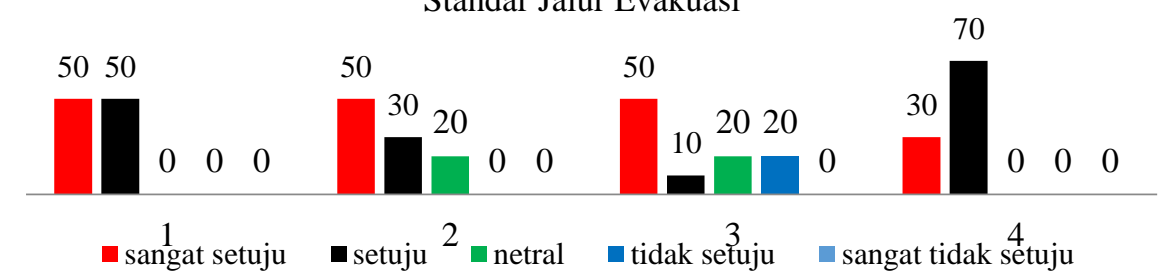

Gambar 3 Grafik persentase penilaian responden pada standar jalur evakuasi

Berikut data tentang variabel pernilaian terhadap standar jalur evakuasi sebagai berikut:

1) Jalur evakuasi sangat penting diterapkan pada bangunan pemerintah/ bangunan publik, menurut penilaian responden menyatakan 50\% sangat setuju, dan 50\% setuju.

2) Jalur evakuasi dilengkapi dengan penanda yang jelas dan mudah terlihat, menurut penilaian responden menyatakan $50 \%$ sangat setuju, $30 \%$ setuju, dan $20 \%$ Netral.

3) Jalur evakuasi bebas dari benda yang mudah terbakar atau benda yang dapat membahayakan, menurut penilaian responden menyatakan $50 \%$ sangat setuju, $10 \%$ setuju, $20 \%$ netral, dan $20 \%$ tidak setuju.

4) Jalur evakuasi tidak melewati ruang yang dapat dikunci, menurut penilaian responden menyatakan $30 \%$ sangat setuju, dan $70 \%$ setuju.

Evaluasi Standar Jalur Evakuasi Kebakaran Pada Bangunan Gedung Bertingkat (Studi Kasus Gedung BAPPEDA Kabupaten Nagan Raya) - Zakia, Rahmat Djamaluddin, Firzan, Aulil Fajri 
Dari empat aspek yang dinilai pada standar jalur evakuasi, dapat dijabarkan secara global bahwa responden menyatakan $45 \%$ sangat setuju, $40 \%$ setuju, $10 \%$ Netral, dan 5\% tidak setuju.

\subsubsection{Hasil uji validitas dan reliabilitas}

Validasi menunjukan sejauh mana suatu alat pengukur mampu mengukur objek yang hendak diukur. Penentuan validas didasarkan atas perbandingan nilai Corrected item total correlation (korelasi ( $\mathrm{r}$ ) yang diperoleh dengan nilai kritis korelasi product moment ( $\mathrm{r}$ tabel). Apabila nilai korelasi hitung ( $\mathrm{r}$ hitung) lebih besar dibandingkan dengan $\mathrm{r}$ tabel pada tingkat keyakinan $90 \%$ dapat diartikan bahwa item-item pertanyaan tersebut valid. Uji coba dalam kuesioner ini bertujuan untuk mengetahui apakah pertanyaan yang terdapat dalam kuesioner ini memenuhi syarat sah atau tidak untuk dijadikan data dalam penelitian ini. Nilai kritis korelasi produk moment ( $\mathrm{r}$ tabel) untuk sampel berjumlah 10 orang adalah 0,632 di mana derajat bebas $\mathrm{Df}=\mathrm{n}-2=8$. Jadi tabel untuk alpha $10 \%$ adalah 0,632 .

Pengujian dilakukan dengan menggunakan software SPSS-23 (Statistical Product dan service Solution) hasil pengujian dapat dilihat pada Tabel 6 hasilnya bahwa dari 15 item pertanyaan yang diajukan semuanya valid, karena memiliki nilai korelasi yang lebih besar dari 0,632. (Rahadian, Astrini and Rikyatama, 2016)

Tabel 6 Hasil uji validitas

\begin{tabular}{|c|c|c|c|}
\hline \multirow[b]{2}{*}{$\begin{array}{c}\text { Item } \\
\text { Pertanyaan }\end{array}$} & \multicolumn{2}{|c|}{ Variabel } & \multirow[b]{2}{*}{$\begin{array}{l}\text { Nilai } \mathrm{r} \\
\text { table } \\
(\mathrm{n}=10)\end{array}$} \\
\hline & $\begin{array}{c}\text { Corrected item } \\
\text { total } \\
\text { correlation }\end{array}$ & Keterangan & \\
\hline $\begin{array}{l}\text { Fasilitas yang ada digedung bappeda kabupaten } \\
\text { nagan raya sudah aman terhadap kebakaran }\end{array}$ & 0,865 & Valid & 0,632 \\
\hline $\begin{array}{l}\text { Gedung bappeda kabupaten nagan raya sudah } \\
\text { memenuhi standar evakuasi kebakaran }\end{array}$ & 0,703 & Valid & 0,632 \\
\hline $\begin{array}{l}\text { Pintu darurat pada gedung bappeda kabupaten } \\
\text { nagan raya dapat dibuka dari arah mana saja }\end{array}$ & 0,813 & Valid & 0,632 \\
\hline $\begin{array}{l}\text { Pintu darurat dilengkapi dengan penutup pintu } \\
\text { otomatis }\end{array}$ & 0,813 & Valid & 0,632 \\
\hline $\begin{array}{l}\text { Setiap bangunan pemerintah/ bangunan publik } \\
\text { diharuskan untuk menyediakan jalur evakuasi } \\
\text { kebakaran. }\end{array}$ & 0,867 & Valid & 0,632 \\
\hline $\begin{array}{l}\text { Kurangnya kepedulian terhadap penerapan jalur } \\
\text { evakuasi pada Gedung bappeda kabupaten } \\
\text { nagan raya. }\end{array}$ & 0,703 & Valid & 0,632 \\
\hline $\begin{array}{l}\text { Dilakukan pelatihan tentang tata cara } \\
\text { penempatan simbol/ fasilitas jalur evakuasi pada } \\
\text { Gedung bappeda kabupaten nagan raya sudah }\end{array}$ & 0,813 & Valid & 0,632 \\
\hline Kurang menyadari manfaat dari jalur evakuasi. & 0,865 & Valid & 0,632 \\
\hline $\begin{array}{l}\text { Kurangnya pengetahuan dan pengalaman } \\
\text { mengenai jalur evakuasi }\end{array}$ & 0,864 & Valid & 0,632 \\
\hline $\begin{array}{l}\text { Semua penghuni paham mengenai kegunaan } \\
\text { simbol jalur evakuasi }\end{array}$ & 0,865 & Valid & 0,632 \\
\hline $\begin{array}{l}\text { Semua mengerti menggunakan APAR jika } \\
\text { sewaktu-waktu terjadi kebakaran }\end{array}$ & 0,766 & Valid & 0,632 \\
\hline $\begin{array}{l}\text { Jalur evakuasi sangat penting diterapkan pada } \\
\text { bangunan pemerintah/bangunan publik. }\end{array}$ & 0,766 & Valid & 0,632 \\
\hline $\begin{array}{l}\text { Jalur evakuasi dilengkapi dengan penanda yang } \\
\text { jelas dan mudah terlihat }\end{array}$ & 0,703 & Valid & 0,632 \\
\hline $\begin{array}{l}\text { Evaluasi Standar Jalur Evakuasi Kebakaran } \\
\text { (Studi Kasus Gedung BAPPEDA Kabupater } \\
\text { Djamaluddin, Firzan, Aulil Fajri }\end{array}$ & $\begin{array}{l}\text { Ida Bangunan } \\
\text { Nagan Raya) }\end{array}$ & $\begin{array}{l}\text { dung Bertin } \\
\text { Zakia, Rah }\end{array}$ & 482 \\
\hline
\end{tabular}




\begin{tabular}{lccc}
\hline $\begin{array}{l}\text { Jalur evakuasi bebas dari benda yang mudah } \\
\text { terbakar atau benda yang dapat membahayakan }\end{array}$ & 0,865 & Valid & 0,632 \\
\hline $\begin{array}{l}\text { Jalur evakuasi tidak melewati ruang yang dapat } \\
\text { dikunci }\end{array}$ & 0,813 & Valid & 0,632 \\
\hline
\end{tabular}

Uji reliabilitas adalah uji statistik yang digunakan untuk mengukur tingkat ketepatan, keakuratan, kestabilan atau konsistensi dalam mengungkapkan gejala tertentu dari kelompok individu, meskipun waktu berbeda. Dalam penelitian ini mengukur reliabilitas menggunakan SPSS-23 dengan uji statistic menggunakan teknik Alfa Cronbach, yaitu koofisien keandalan yang menunjukan seberapa baik item dalam suatu kumpulan secara positif berkorelasi satu sama lain. semakin tinggi konsisten internal. Nilai Alfa Crronbach > 0,6 adalah instrument kuesioner dinyatakan andal (reliable). Jadi dapat disimpulkan bahwa semua item pertanyaan dalam angket penelitian memenuhi uji reliabilitas, karena nilai $\propto$ hitung $>\propto$ tabel seperti yang diperlihat pada Tabel 7 berikut ini:

Tabel 7 Hasil uji reliabilitas 90,9\%

\begin{tabular}{|c|c|c|}
\hline \multicolumn{3}{|c|}{ Reliability Statistics } \\
\hline Cronbach's Alpha & $\begin{array}{l}\text { Cronbach's Alpha } \\
\text { Based on } \\
\text { Standardized Items }\end{array}$ & $\mathrm{N}$ of Items \\
\hline 0,962 & 0,909 & 15 \\
\hline
\end{tabular}

Kriteria Nunnaly (1960): Cronbach's Alpha lebih besar dari 60\% $90,9 \%$ lebih besar dari $60 \%=$ Reliable

\begin{tabular}{lllll}
\hline No & \multicolumn{2}{c}{ Variabel } & Cronbach Alpha & Reliabilitas \\
\hline 1. & $\begin{array}{l}\text { Konsep jalur evakuasi terhadap program } \\
\text { penyelamatan disebuah bangunan. }\end{array}$ & $\mathbf{0 9 6 2}$ & Reliable \\
\hline
\end{tabular}

\subsection{Pembahasan}

Pembahasan dilakukan mengenai permasalahan-permasalahan yang sudah dirumus pada latar belakang. Pengolahan data dan materi yang akan disajikan adalah berdasarkan dari pokok permasalahan. Penyelesain permasalahan dilakukan berdasarkan teori-teori yang dikemukakan, dengan cara pengolahan data-data sehingga diperoleh hasil dari penelitian pada gedung Bappeda Kabupaten Nagan Raya.

\subsubsection{Jenis-jenis fasilitas jalur evakuasi yang tersedia}

Dari hasil evaluasi yang dilakukan, terdapat beberapa fasilitas yang belum tersedia seperti Jalur Pedestarian, Perlengkapan dan Peralatan Kontrol, apar, eksit sedangkan yang sudah tersedia ukuran pintu, tangga, titik kumpul, koridor, hal ini dapat diketahui dari hasil evaluasi yang dilakukan bahwa hanya sebahagian fasilitas yang belum tersedia menurut standar ketentuan PERMEN PUPR No. 26/PRT/M/2008 Tahun 2008 tentang Persyaratan Teknis Sistem Proteksi Kebakaran pada Bangunan Gedung dan Lingkungan.

\subsubsection{Kesesuaian fasilitas jalur evakuasi}

Dari hasil evaluasi yang dilakukan pada gedung Bappeda kabupaten Nagan Raya tentang kesesuaian fasilitas jalur evakuasi dengan acuan PERMEN PUPR No. 26/PRT/M/2008 Tahun 2008 tentang Persyaratan Teknis Sistem Proteksi

Evaluasi Standar Jalur Evakuasi Kebakaran Pada Bangunan Gedung Bertingkat (Studi Kasus Gedung BAPPEDA Kabupaten Nagan Raya) - Zakia, Rahmat Djamaluddin, Firzan, Aulil Fajri 
Kebakaran pada Bangunan Gedung dan Lingkungan, maka dapat disimpulkan bahwa semua fasilitas jalur evakuasi yang tersedia pada gedung Bappeda kabupaten Nagan Raya belum semuanya sesuai dengan standar yang berlaku yang dapat memberikan kemudahan untuk proses evakuasi bagi penguna gedung atau pengunjung pada saat terjadinya kebakaran.

\section{Pintu Darurat}

Hasil evaluasi pintu pada gedung BAPPEDA Kabupaten Nagan Raya telah sesuai seperti yang dianjurkan Permen PUPR No. 26/PRT/M/2008 Tahun 2008 tentang Persyaratan Teknis Sistem Proteksi Kebakaran pada Bangunan Gedung dan Lingkungan, bahwa semua ukuran pintu dan jenis engsel semua sudah sesuai, namun jenis daun pintu nya belum sesuai karena terbuat dari kayu yang tidak tahan api.

\section{Tangga Darurat}

Hasil evaluasi bahwa tangga pada gedung BAPPEDA Kabupaten Nagan Raya telah sesuai seperti yang dianjurkan PERMEN PUPR No. 26/PRT/M/2008 Tahun 2008 tentang Persyaratan Teknis Sistem Proteksi Kebakaran pada Bangunan Gedung dan Lingkungan, sedangkan yang belum sesuai adalah tinggi handrail.

\section{Koridor}

Hasil evaluasi koridor sudah memenuhi dan sesuai seperti yang dianjurkan PERMEN PUPR No. 26/PRT/M/2008 Tahun 2008 tentang Persyaratan Teknis Sistem Proteksi Kebakaran pada Bangunan Gedung dan Lingkungan, maka dapat disimpulkan lebar koridor sudah memenuhi namun ketersediaan lantai dan petunjuk arah belum memenuhi.

\section{Area titik kumpul}

Hasil evaluasi area titik kumpul pada gedung Bappeda Kabupaten Nagan Raya telah sesuai dan memenuhi seperti yang dianjurkan PERMEN PUPR No. 26/PRT/M/2008 Tahun 2008 tentang Persyaratan Teknis Sistem Proteksi Kebakaran pada Bangunan Gedung dan Lingkungan, maka dapat disimpulkan bahwa Luas area titik kumpul sudah sesuai dan mudah dijangkau untuk jalur evakuasi.

5. Faktor pendukung dan kendala dalam penyediaan jalur evakuasi kebakaran.

Hal mendasar yang menyebabkan fasilitas jalur evakuasi dengan acuan PERMEN PUPR No. 26/PRT/M/2008 Tahun 2008 tentang Persyaratan Teknis Sistem Proteksi Kebakaran pada Bangunan Gedung dan Lingkungan, yang mengwajibkan setiap bangunan publik menyediakan kelengkapan fasilitas jalur evakuasi kebakaran karena bangunan publik diperuntukan untuk semua kalangan karena musibah kebakaran tidak bisa diprediksi kapan terjadi.

\section{Kesimpulan dan Saran}

\subsection{Kesimpulan}

Setelah melakukan evaluasi dan identifikasi Standar Jalur Evaluasi Kebakaran pada Bangunan Gedung Bappeda Kabupaten Nagan Raya, sesuai PERMEN PUPR No. 26/PRT/M/2008 Tahun 2008 tentang Persyaratan Teknis Sistem Proteksi Kebakaran pada Bangunan Gedung dan Lingkungan, dari hasil dan pembahasan maka dapat disimpulkan antara lain bahwa penerapan peraturan sistem jalur evakuasi kebakaran masih pasif dan belum sesuai dengan standart Peraturan

Evaluasi Standar Jalur Evakuasi Kebakaran Pada Bangunan Gedung Bertingkat (Studi Kasus Gedung BAPPEDA Kabupaten Nagan Raya) - Zakia, Rahmat Djamaluddin, Firzan, Aulil Fajri 
Menteri Pekerjaan Umum No.26/PRT/M/2008 pada gedung Bappeda Kabupaten Nagan Raya untuk fungsi bangunan publik, yaitu pada pintu dan tangga serta kebijakan mengenai darurat kebakaran. Kesesuaian fasilitas jalur evakuasi kebakaran yang tersedia pada bangunan gedung Bappeda Kabupaten Nagan Raya sangat sulit dilakukan evakuasi jika sewaktu waktu-waktu terjadi kebakaran. Pemeriksaan bangunan harus dilakukan sejak tahap perancangan bangunan. Pemeriksaan yang dilakukan setelah bangunan berdiri memberikan hasil rekomendasi yang tidak tegas. PERMEN PUPR No. 26/PRT/M/2008 Tahun 2008 tentang Persyaratan Teknis Sistem Proteksi Kebakaran pada Bangunan Gedung dan Lingkungan telah menyertakan alternatif pemunuhan atau fleksibilitas dengan menggunakan pendekatan basis kinerja. Kondisi ini perlu didukung dengan pemodelan dan simulasi kebakaran berbasis kinerja untuk pemunuhan penyediaan proteksi kebakaran.

\subsection{Saran}

Dari hasil penelitian dan kesimpulan yang diperoleh, maka saran yang dapat diberikan adalah Kebijakan mengenai darurat kebakaran, pintu dan tangga pada kantor BAPPEDA Kabupaten Nagan Raya sebagian masih belum memenuhi standar, maka hasil penelitian ini dapat menjadi usulan mengenai standar operasional prosedur pada saat terjadi darurat di kantor BAPPEDA Kabupaten Nagan Raya. Disarankan bagi pengurus untuk dibuatkan suatu kebijakan atau SOP tentang darurat kebakaran yang nantinya dapat digunakan pada saat terjadi darurat kebakaran pada gedung BAPPEDA Kabupaten Nagan Raya. Perlu dilengkapi yang belum tersedia di gedung tersebut, seperti jalur evakuasi gedung yang mempermudah penghuni gedung menujuk titik kumpul. Bagi kalangan akademis yang ingin melakukan penelitian mengenai Standar Jalur Evalukuasi Kebakaran pada Bangunan Gedung diharapkan sebagai bahan pertimbangan meningkatkan kualitas penerapan system Standar Jalur Evalukuasi Kebakaran di Aceh khususnya bagi bagunan gedung publik. Dengan demikian diharapkan resiko terhadap bahaya kebakaran dapat dihindari dan diantisipasi.

\section{Daftar Kepustakaan}

Akdon dan Riduan., 2010. Rumus dan Data dalam Analisis Statistika Cetakan 2, Alfabeta, Bandung.

Faruk, A., 2018. Evaluasi Penerapan Jalur Evakuasi Dan Assembly Point Di Gedung Bertingkat Sekolah Menengah Kejuruan (SMK), Roudlotul Mubtadiin Balekambang', p. 14.

Fernanda, E., 2018. Departemen Arsitektur Fakultas Teknik Universitas Sumatera Utara, p. 130.

Margono., 2004. Metodologi penelitian pendidikan. / Margono, S. | Perpustakaan Lembaga Administrasi Negara. Available at: http://pustakamaya.lan.go.id/opac/detail-opac?id=4637.

Evaluasi Standar Jalur Evakuasi Kebakaran Pada Bangunan Gedung Bertingkat (Studi Kasus Gedung BAPPEDA Kabupaten Nagan Raya) - Zakia, Rahmat Djamaluddin, Firzan, Aulil Fajri 
Pemerintah Repulik Indonesia, P.R., 2020. Bappeda Nagan Raya., 2020. Pemerintah Kabupaten Nagan Raya. Available at: https://naganrayakab.go.id/.

Pemerintah Repulik Indonesia, P.R., 2005. PP No. 36 Tahun 2005 tentang Peraturan Pelaksanaan Undang Undang No. 28 Tahun 2002 tentang Bangunan Gedung, Sekretariat Negara, Jakarta.

Pemerintah Repulik Indonesia, P.R., 2008. PERMEN PUPR No. 26/PRT/M/2008 Tahun 2008 tentang Persyaratan Teknis Sistem Proteksi Kebakaran pada Bangunan Gedung dan Lingkungan [JDIH BPK RI]. Available at: https://peraturan.bpk.go.id/Home/Details/104475/permen-pupr-no26prtm2008-tahun-2008.

Rahadian, E. Y., Astrini, Z. F. and Rikyatama, B., 2016. Evaluasi Desain Jalur Evakuasi Pengguna Bangunan Dalam Kondisi Darurat Pada Bangunan Apartemen X, p. 13.

Ramawangsa, P. A., 2019. Standardisasi Sirkulasi Vertikal Pada Gedung Serba Guna Unib Berdasarkan Sni 03-1746-2000, p. 8.

Sekaran, U., 2007. Research Methods for Business = Metodologi Penelitian untuk Bisnis. Buku 1, Ed.4. Salemba Empat.

Sugiyono, P., 2015. Metode penelitian kombinasi (mixed methods), Bandung: Alfabeta, 28, pp. 1-12. 